برنامج لتنميه الوعي باجر اءات السلامه والصحه المهنيه في بيئه العمل. دراسة حالة بإحدى شركات البترول.

احمد ربيع عبد الخالق' , عزت الفضالى ',عصام جمال'

'باحث ـ معهد الدراسات والبحوث البيئية - جامعة مدينة السادات

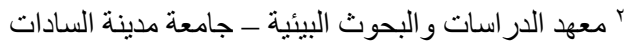

الملخص

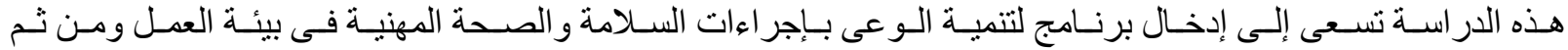

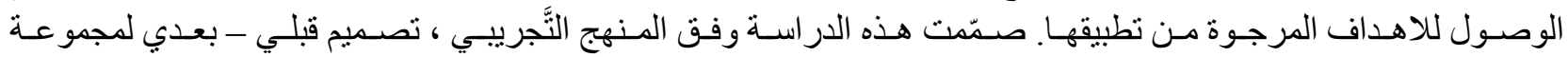

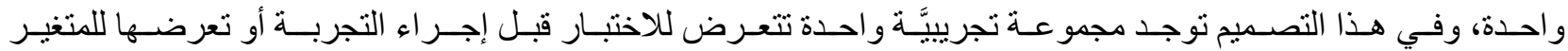

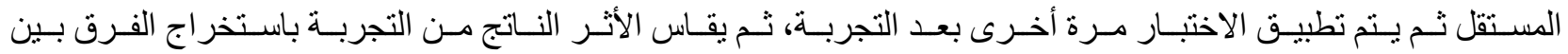

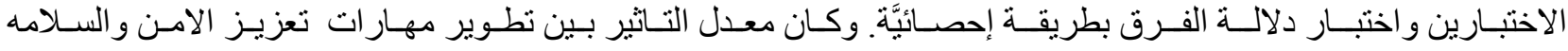

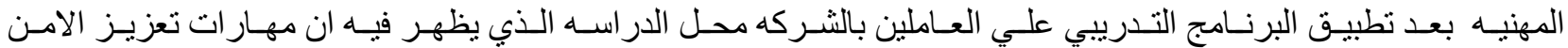

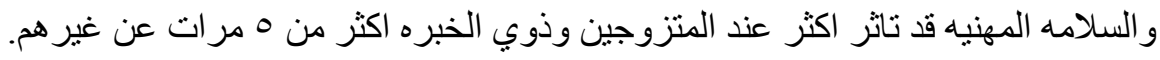

المقدمها

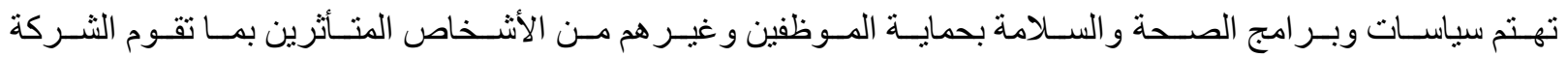

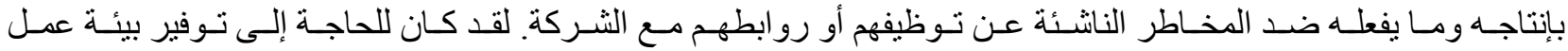

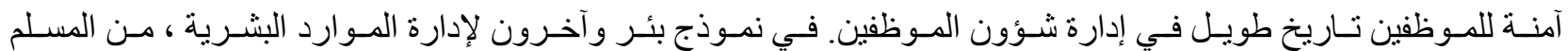

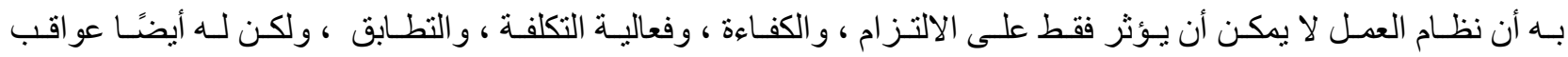

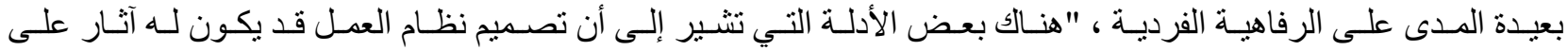

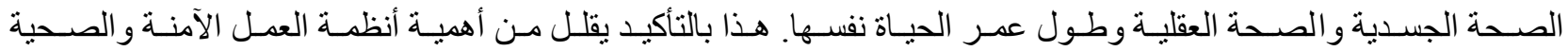

لصحة الموظفين(Abdallah, 2018)

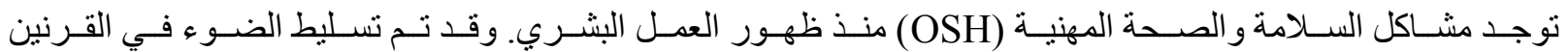

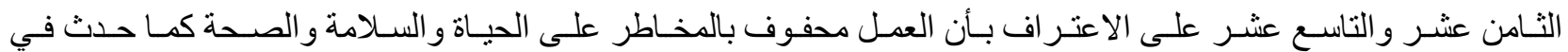

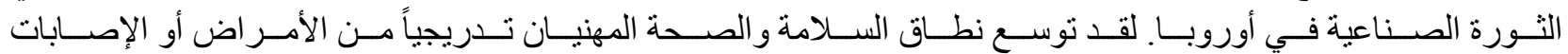

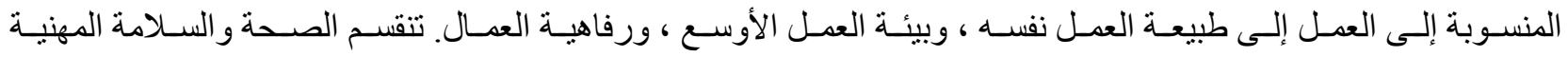

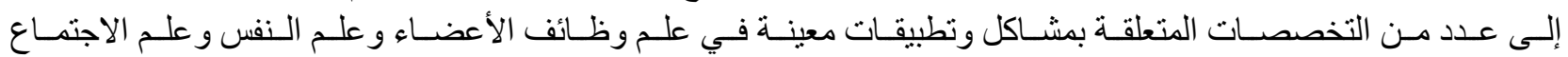

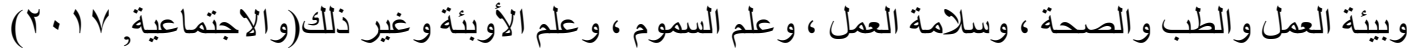

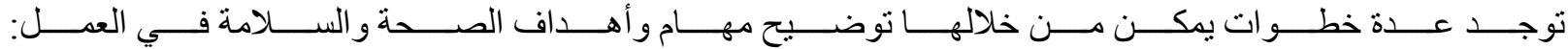

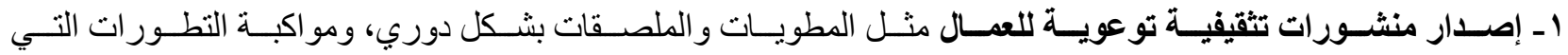
(Abdallah, 2018)

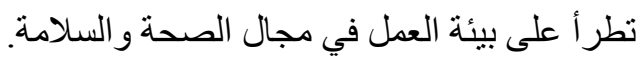

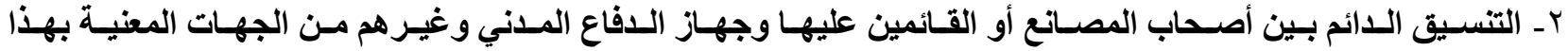
نأن

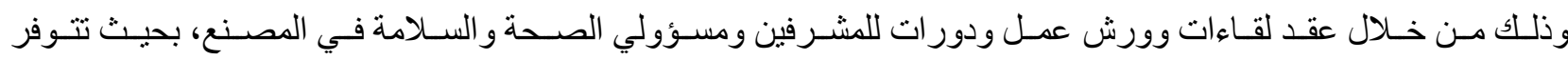

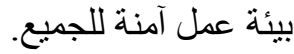

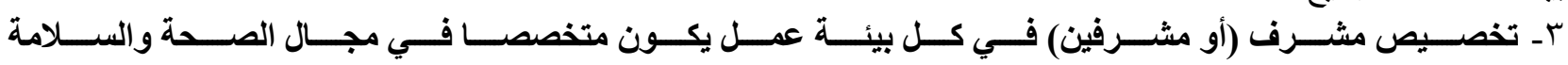

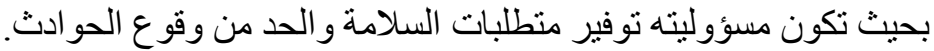

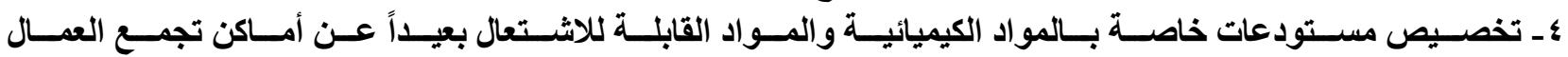

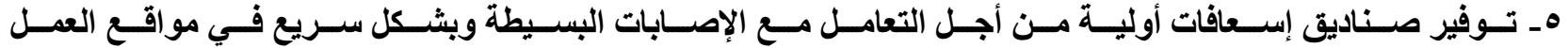




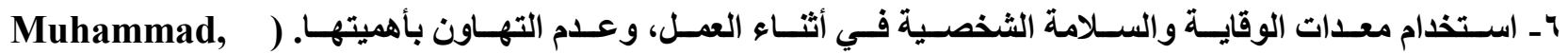

(Helal, \& Studies, 2018

أهمية الدراسة

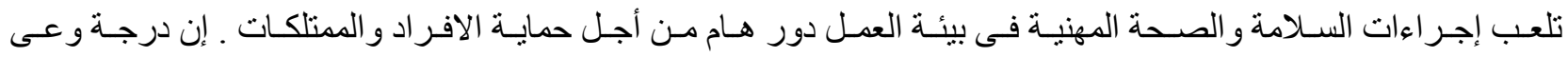

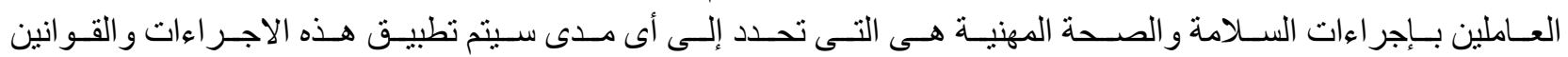
وبالتالى توفير بيئة عمل امنه خالية من الاصابات او الضرر و التلف للممتلكات.

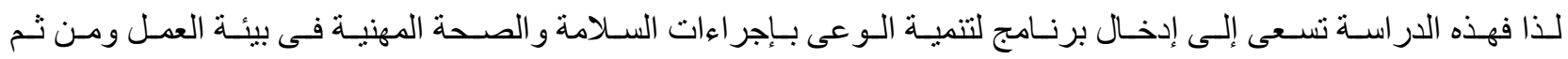
الوصول للاهداف المرجوة من تطبيقها.

ا م. أسئلة الاراسة

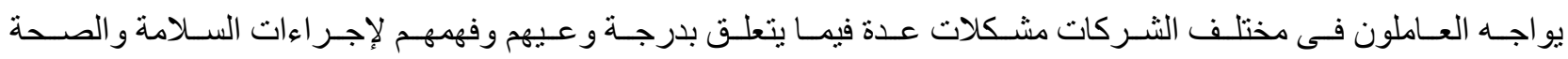
المهنية فى بيئة العمل ويمكن التعبير عن هذه المشكلات فى ضوء التهات الاسئلة التالية:

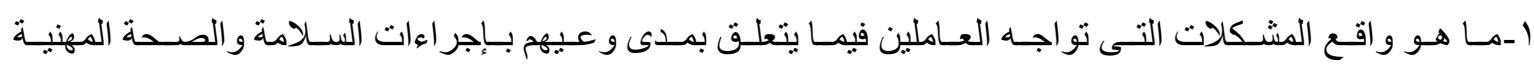

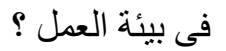
r. هل يؤثر مدى الوعى بإجر اءات السلامة و الصحة المهنية على تطبيق العاملين لهذه الإجر اءات؟

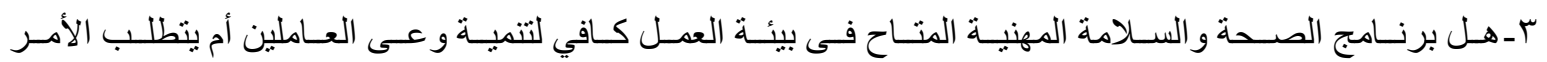
إدخال بر امج اخرى قد تنكون ذات تأثير وفعالية أكثر؟

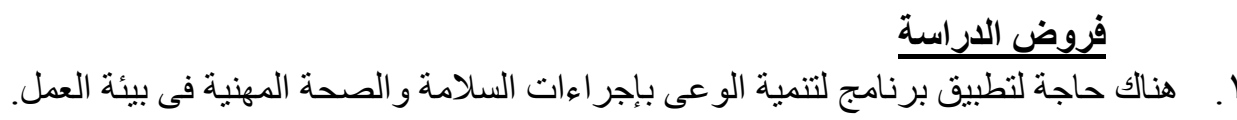

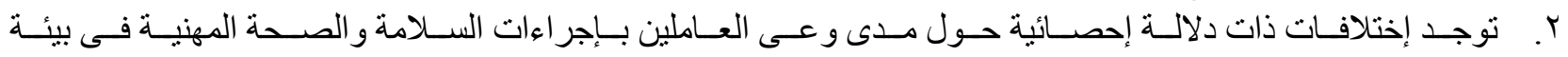

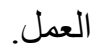

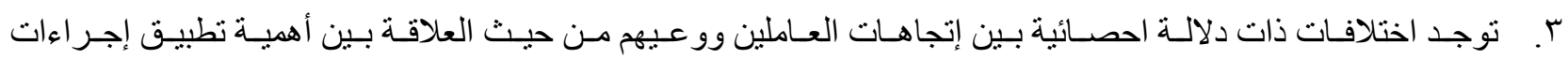

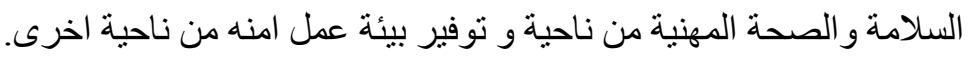

$$
\text { أهداف الدراسة }
$$

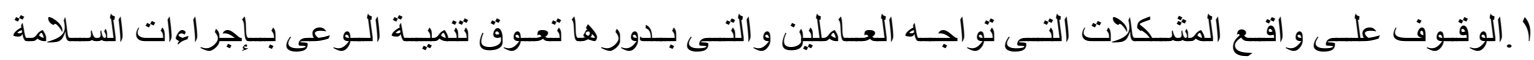

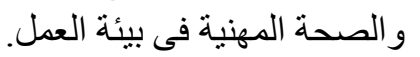

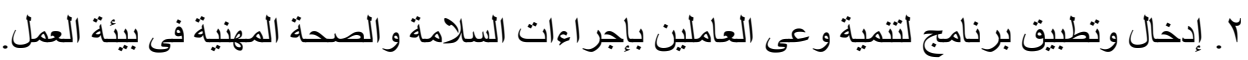

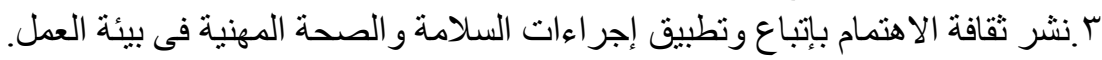

الاطار النظري للاراسده

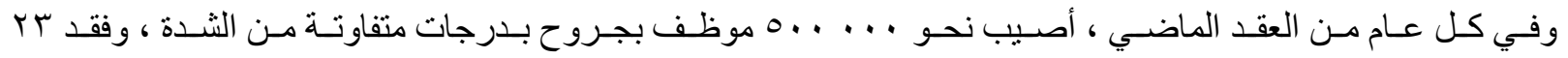

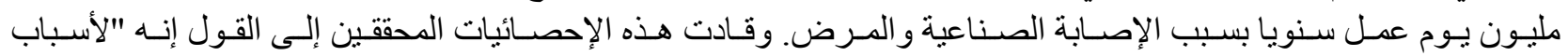

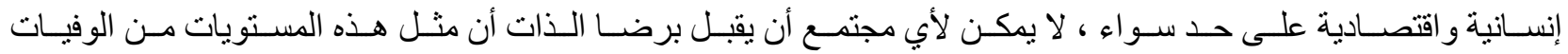

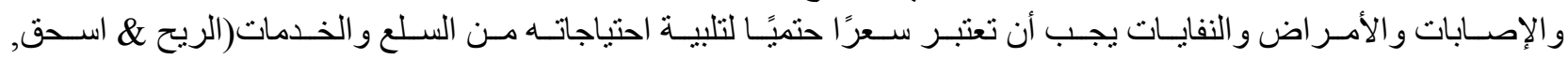

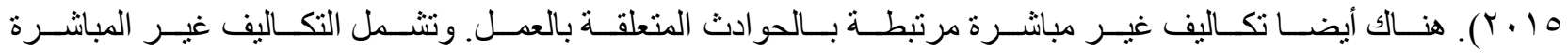

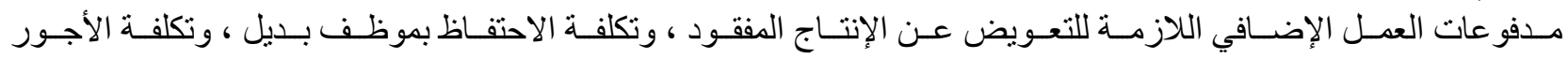

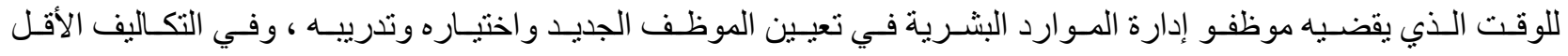




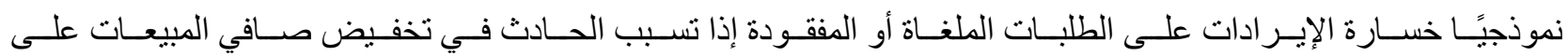
المدى الطويل ، و الحضور في جلسات المحكمة في القضايا المتنازع عليها.(Zeb et al., 2017)

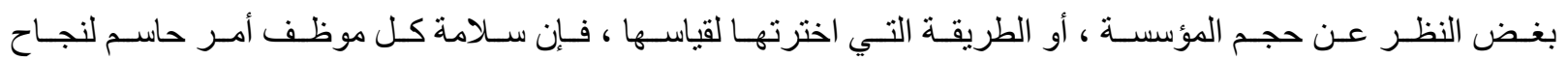

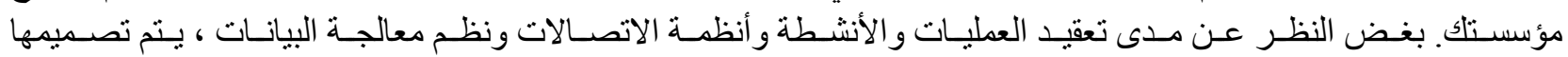

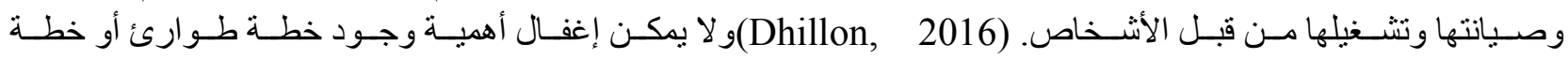

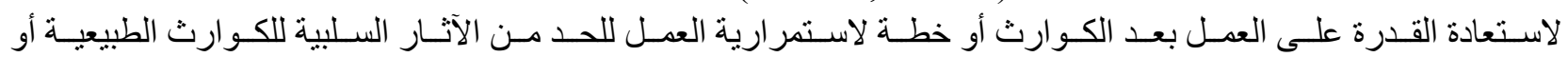

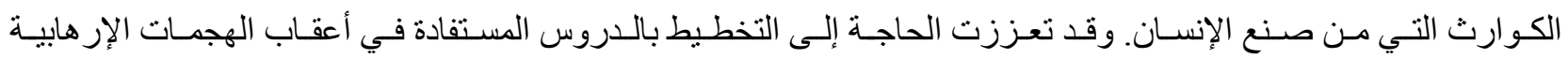

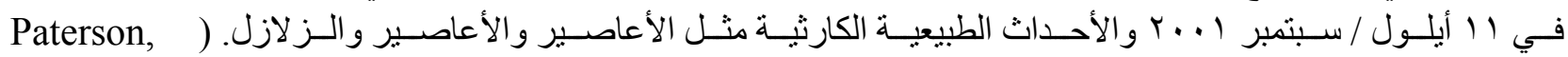

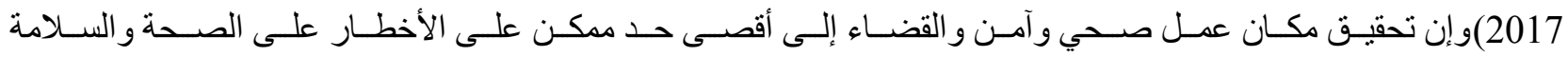

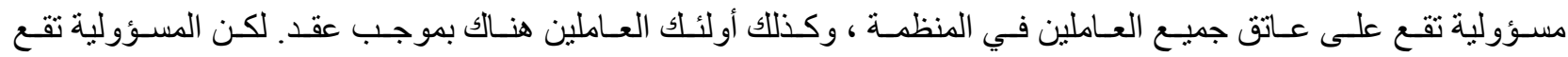

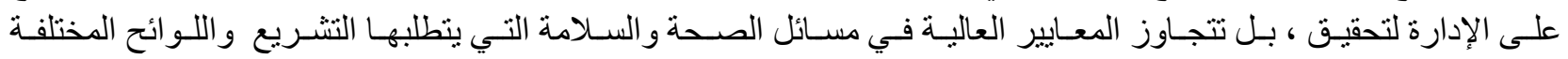

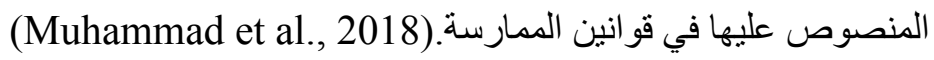

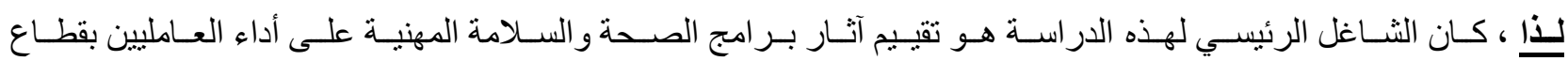

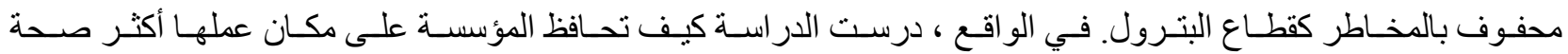

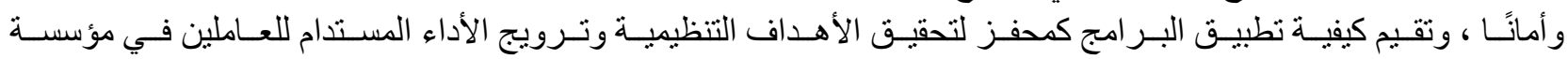

محدة بشكل عام.(Asad, Hassan, Sherwani, Ibrahim, \& Soomro, 2018)

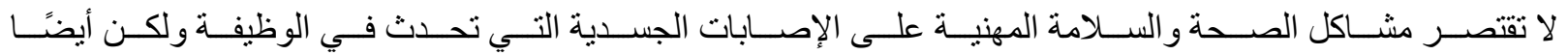

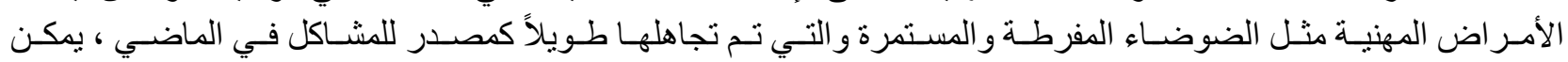

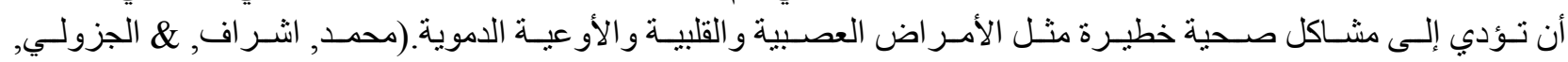

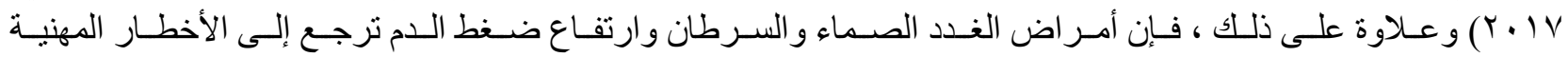

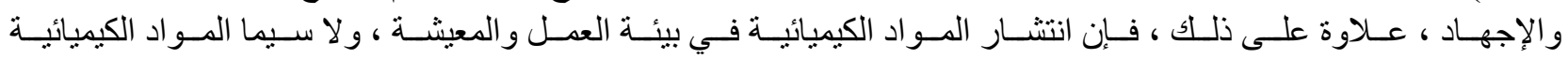

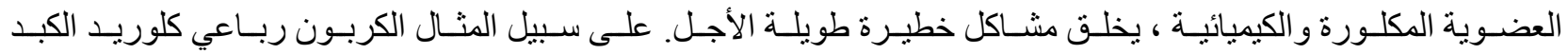

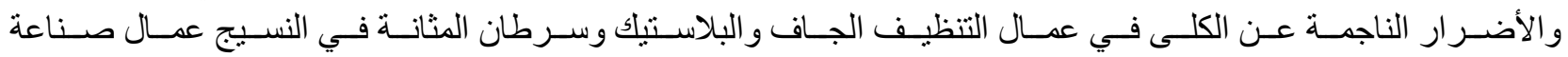

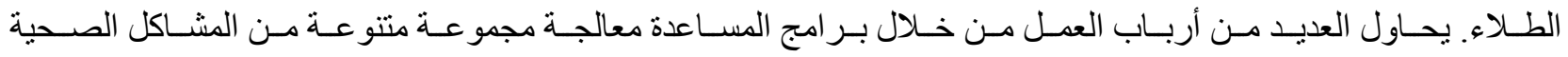

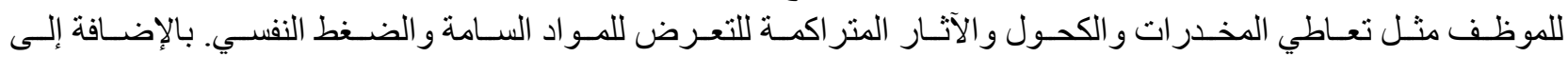

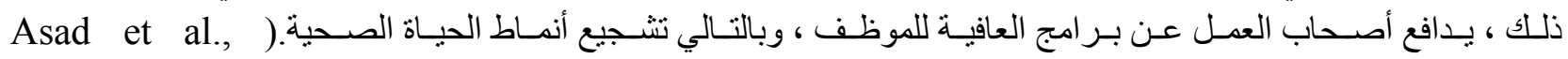

ـ 1, آ صناعة البترول ومخاطر المهنه

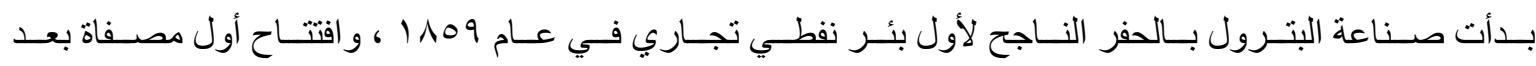

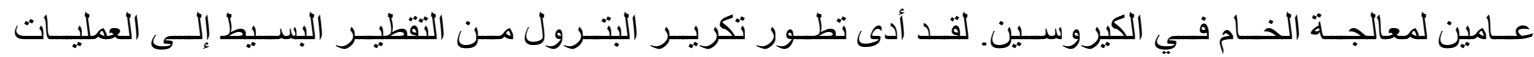

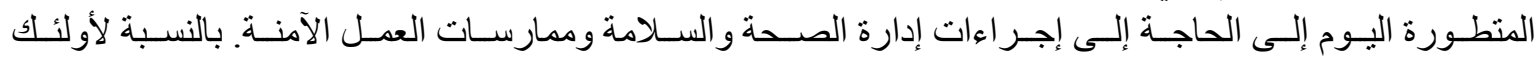

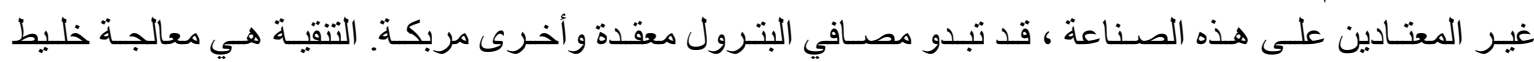

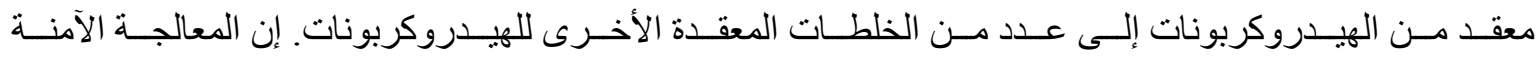

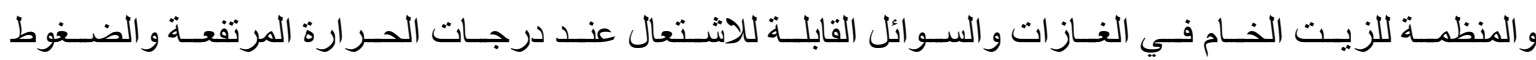

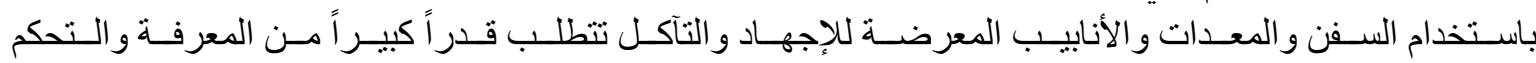

والخبرة.(Demeritt, Rothstein, Beaussier, Howard, \& A, 2015)

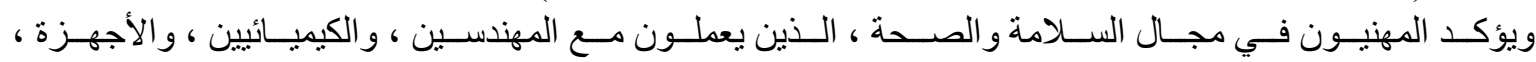

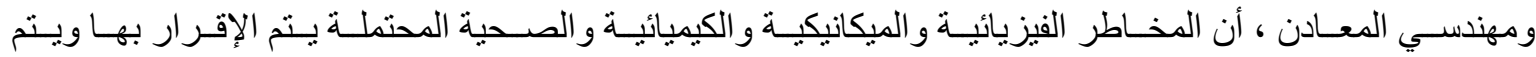

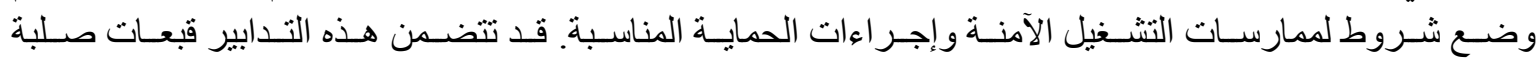

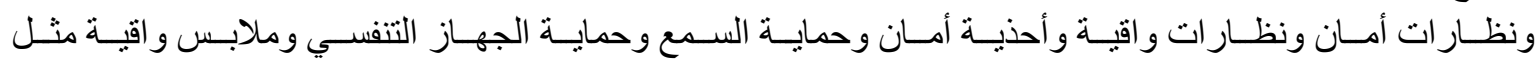

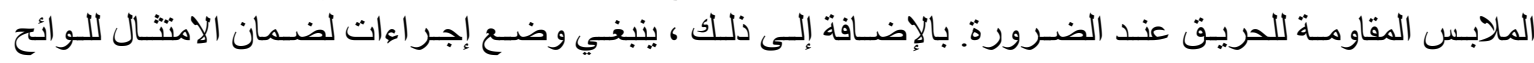




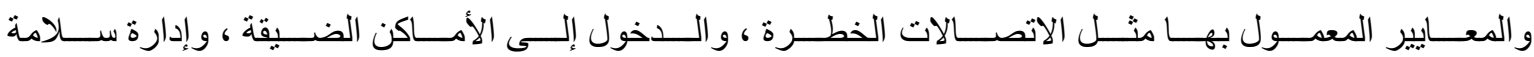

(Mason, Retzer, Hill, Lincoln, \& report, 2015). العمليات

r r, 7 السلامه و الصحة المهنية

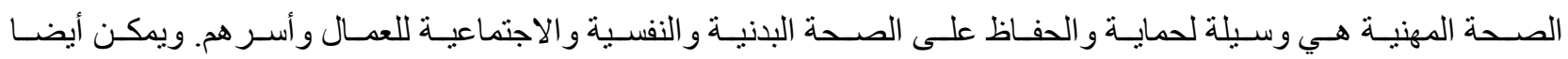

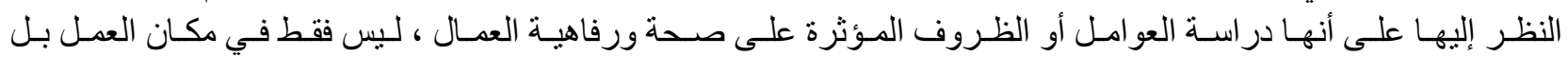
أيضا في المنزل بهدف تعزيز الصحة والسلامة والرفاهية للعاملين و أسر هم.(Amiri et al., 2015)

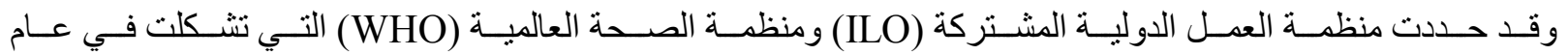

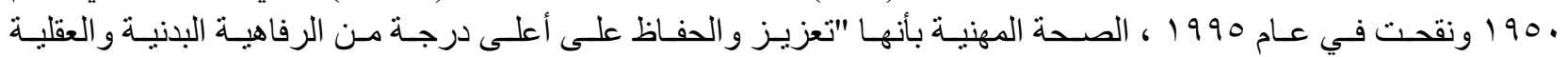

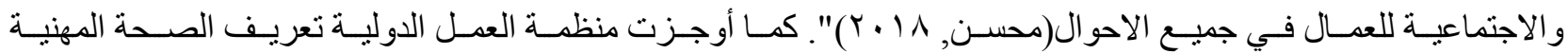

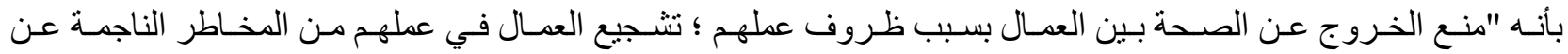

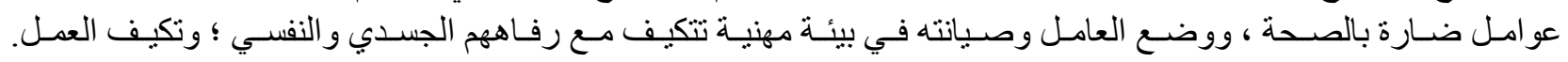

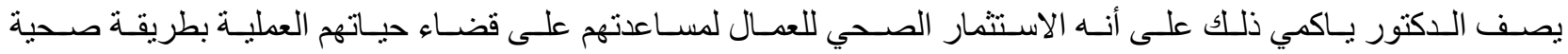

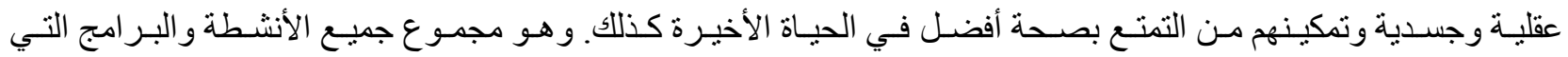

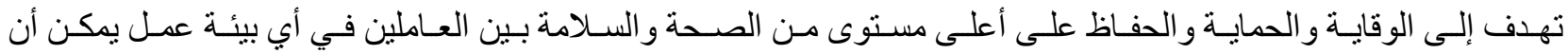

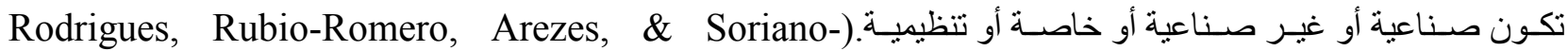

(Serrano, 2016

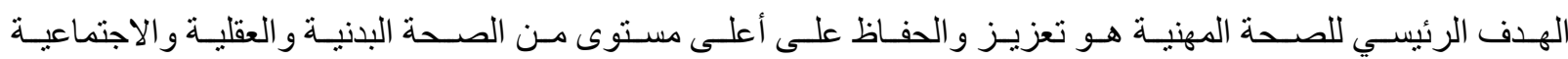

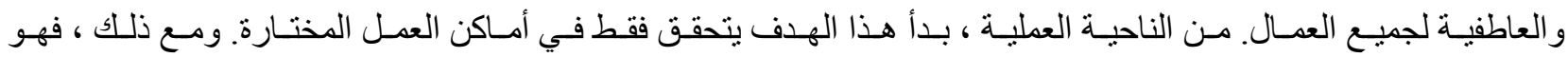
استثمار جيد و هدف أساسي في تحقيق عمل منتج.

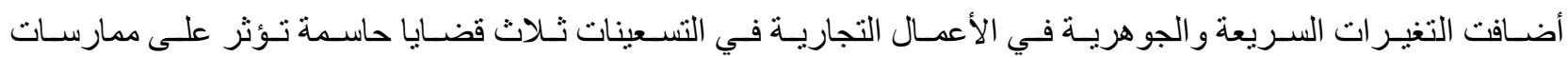

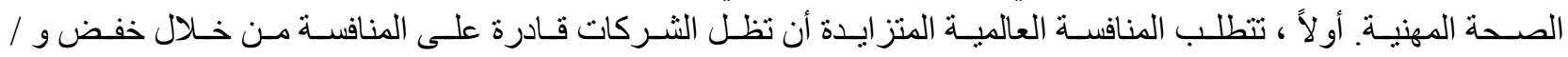

أو مر اقبة تكاليف التشغيل بأدنى مستوى مككن.(Gharpurea, Roya, Purang, \& Bhattacharyya, 2018)

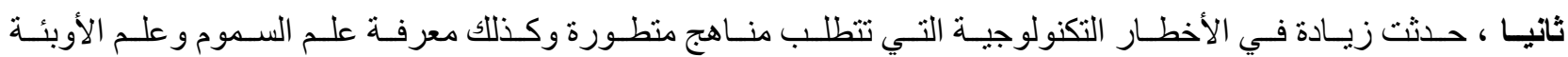

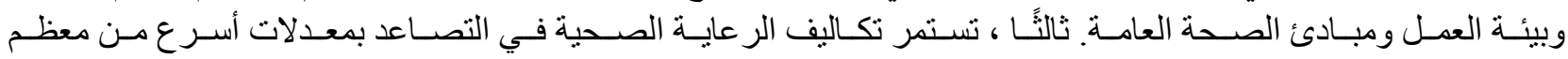
أرباح الشركات.(Humaines, 2018)

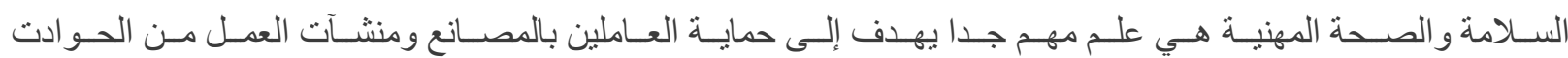

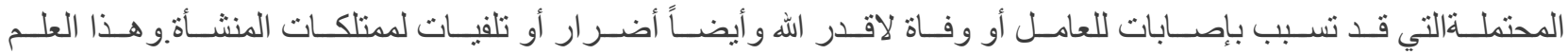

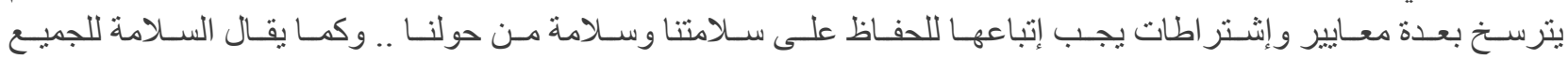
فيقصد هنا أنها مسؤولية الجميع وتكاتفهم ليعيشوا في بيئة عمل آمنة ومطمئنة(Gharpurea et al., 2018).

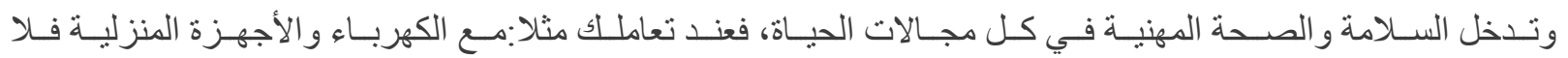

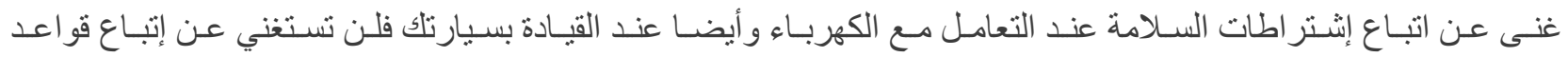

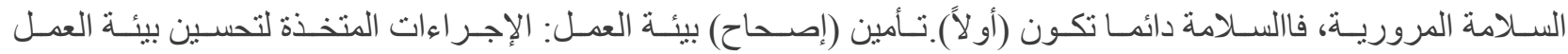

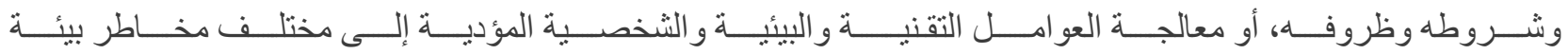

العمل(Mason et al., 2015).

ويمكن حصر أسباب وقوع الحوادث في النقاط التاليه (Dhillon, 2016): 1-محاولة العامل تغير نظام التشغيل من تلقاء نفسه 2-2محاولة العامل تشغيل الات ومعدات غير مهيئة للعمل 
-3محاولة العامل استعمال الات غبر سليمة وبطريقة غبر آمنة

4محاولة العامل استعمال ادوات فى غير غرضها.

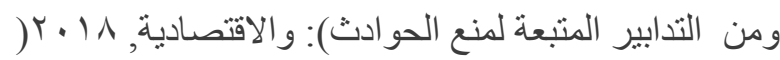

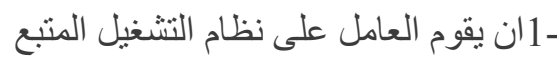

-2 - 2ان يقوم العامل بتشغيل الالات و المعدات المأمونة فقط

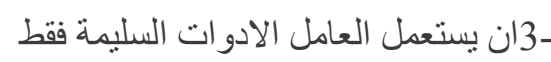

-4ان يستعمل العامل الادوات في الاغر اض المخصصة اليها.

الطريقة والإجراءات

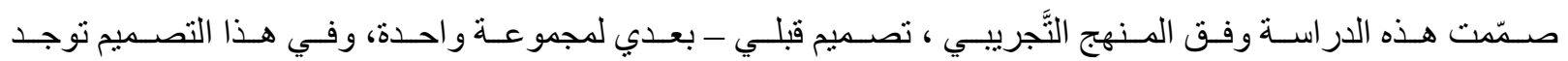

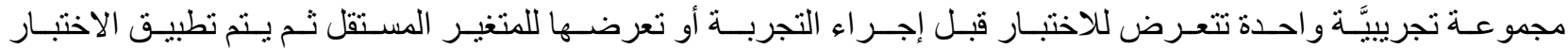

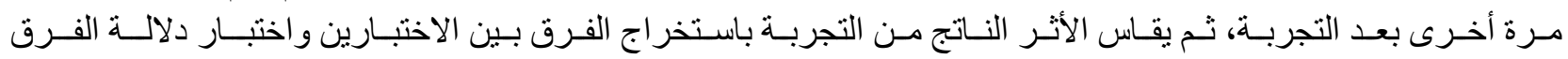
بطريقة إحصائيَّة.

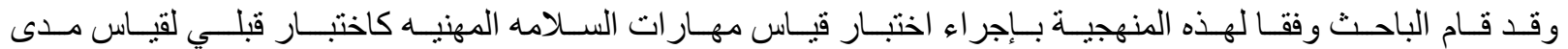

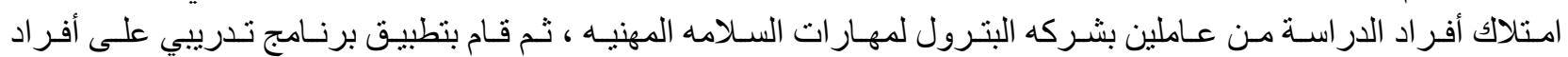

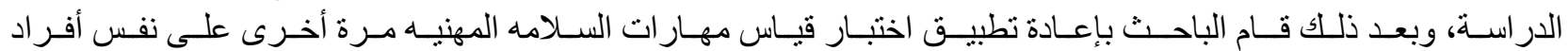

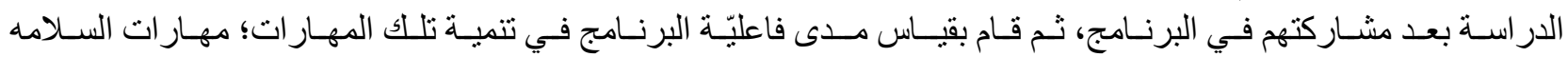

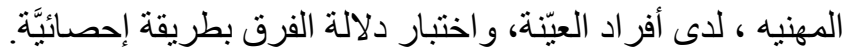

عيّتة الاراسة:

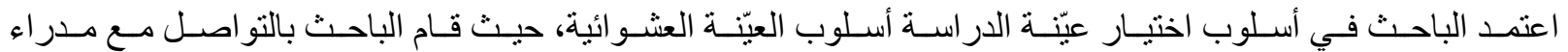

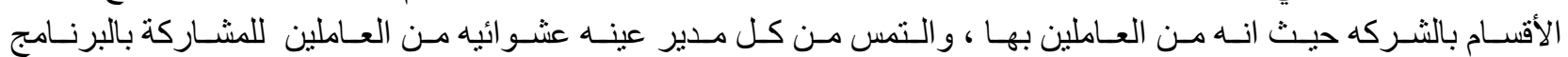

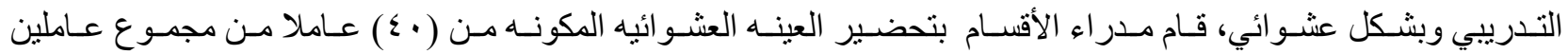

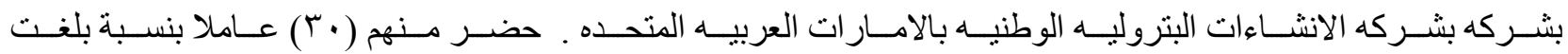

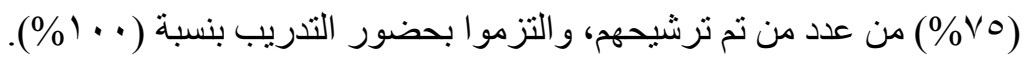

\section{متغيرات الدراسة}

تضمنت الدر اسة المتغير ات الآتية: ا. المتغير المستقل

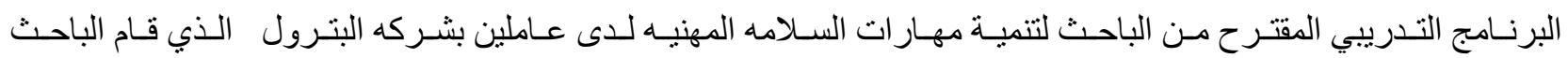
بتصميمه وتدريب أفر اد عيّنة الدر اسة عليه.

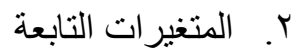

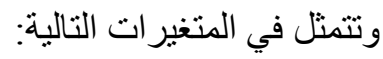

عدد سنوات الخبره

الحاله الاجتماعيه

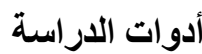

لتحقيق هدف الدراسة تم إعداد مجمو عة من الأدوات وهي على النحو التالي: 


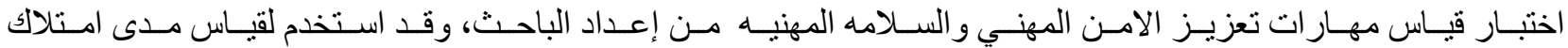

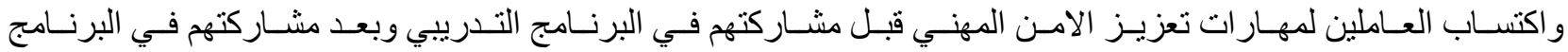

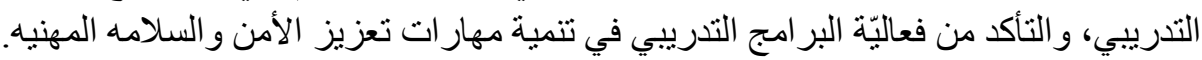

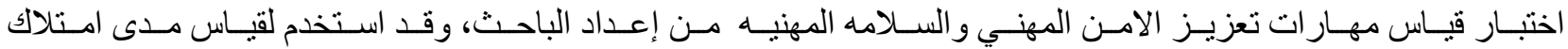

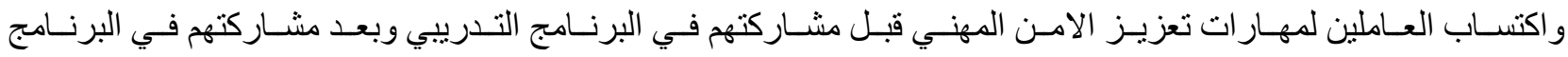
التدريبي، و التأكد من فعاليّة البر امج التدريبي في تنمية مهار اتلت تعزيز الأمن والسلامه المهنيه.

النتائبج

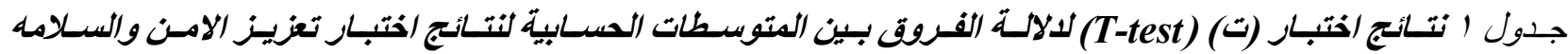

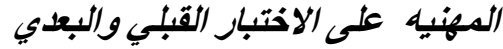

\begin{tabular}{|c|c|c|c|c|c|c|c|}
\hline 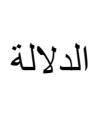 & الحرية & 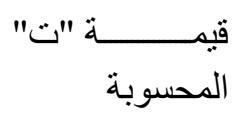 & دالعـد & 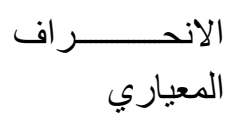 & الحسابي & & الأبعاد \\
\hline \multirow{2}{*}{$\begin{array}{r}0.00 \\
0\end{array}$} & \multirow[b]{2}{*}{29} & \multirow[b]{2}{*}{-12.189} & 30 & 2.360 & 103.50 & قبلي & \multirow[b]{2}{*}{ 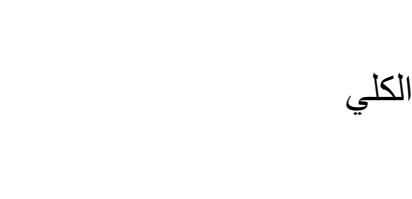 } \\
\hline & & & 30 & 3.294 & 111.90 & بعـــ & \\
\hline \multirow{2}{*}{$\begin{array}{r}0.00 \\
0\end{array}$} & \multirow[b]{2}{*}{29} & \multirow[b]{2}{*}{-5.088} & 30 & 1.750 & 22.80 & قبلي & \multirow{2}{*}{ ك كيفية استخدامهائل الوقايــــة الثخصـــــــة } \\
\hline & & & 30 & 1.810 & 25.37 & بيــ & \\
\hline \multirow[b]{2}{*}{$\begin{array}{r}0.00 \\
0\end{array}$} & \multirow[b]{2}{*}{29} & \multirow[b]{2}{*}{-6.198} & 30 & 1.781 & 40.00 & قبلي & \multirow[b]{2}{*}{ ومخهــــــوم العــــــلامة المهنـــــــة } \\
\hline & & & 30 & 2.144 & 42.77 & بعـ بـ & \\
\hline \multirow{2}{*}{$\begin{array}{r}0.00 \\
0\end{array}$} & \multirow[b]{2}{*}{29} & \multirow[b]{2}{*}{-4.208} & 30 & 1.539 & 23.33 & قبلي & \multirow{2}{*}{ 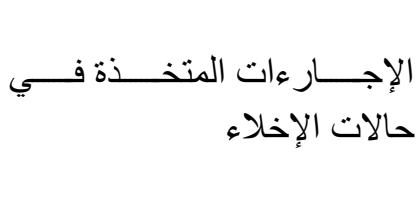 } \\
\hline & & & 30 & 1.605 & 25.10 & بي & \\
\hline \multirow{2}{*}{$\begin{array}{r}0.00 \\
0\end{array}$} & \multirow[b]{2}{*}{29} & \multirow[b]{2}{*}{-4.448} & 30 & 1.299 & 17.37 & قبلي & \multirow[b]{2}{*}{ مخاطر تسريبات الغاز } \\
\hline & & & & 1.061 & 18.67 & بعـد & \\
\hline
\end{tabular}

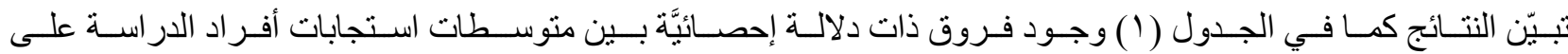

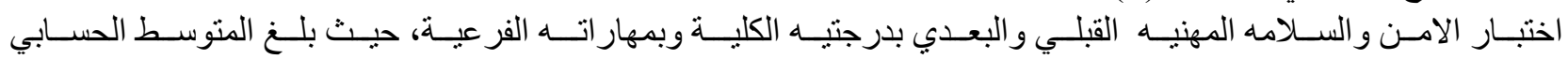




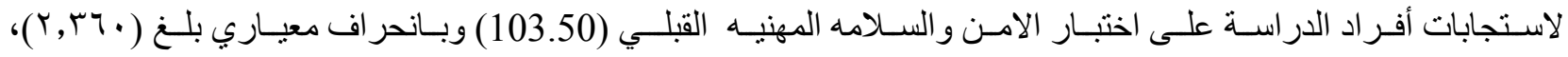

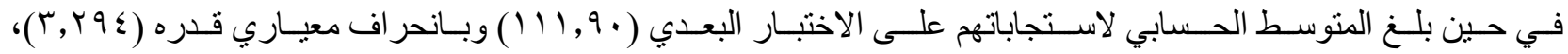

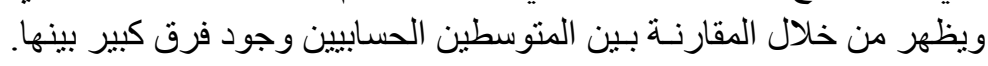

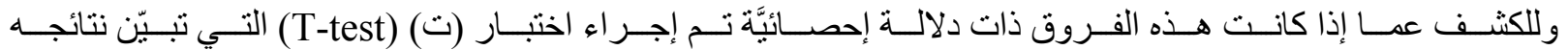

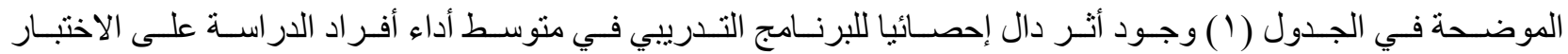

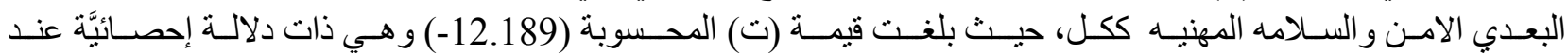

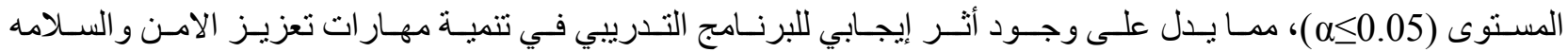
المهنيه لدى العاملين .

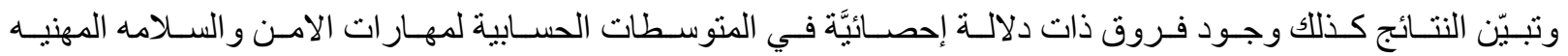

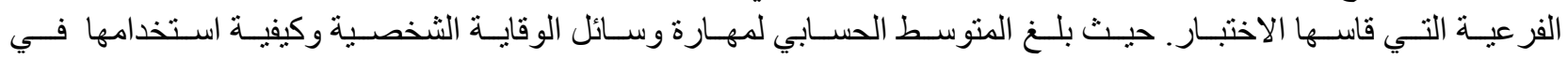

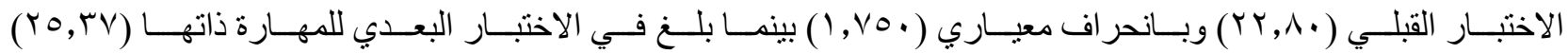

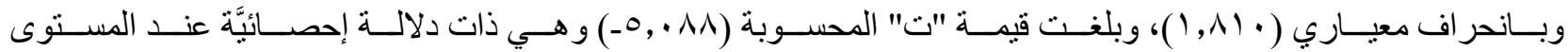
. $(\alpha \leq 0.05)$

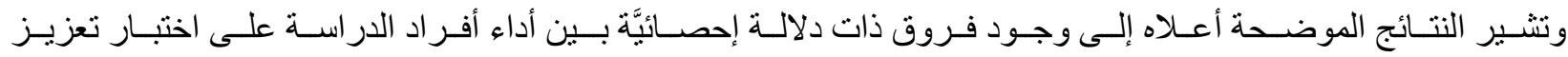

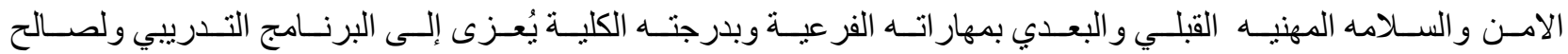

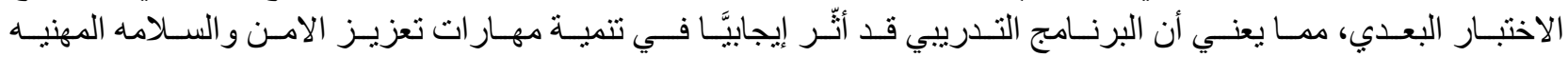

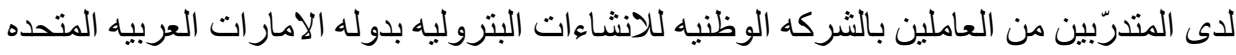

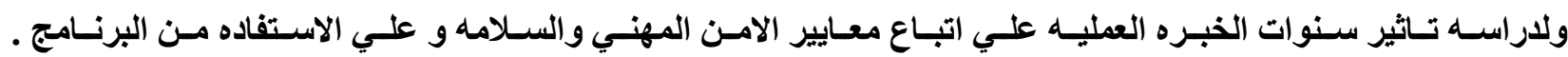

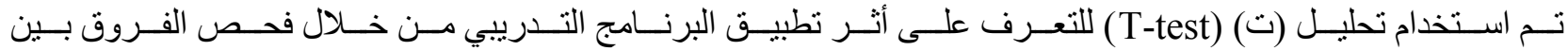

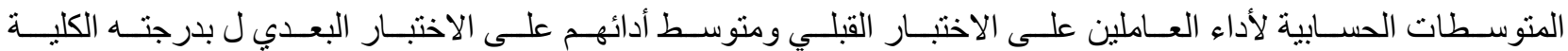

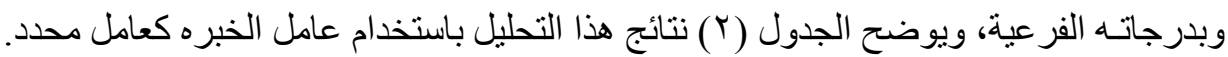

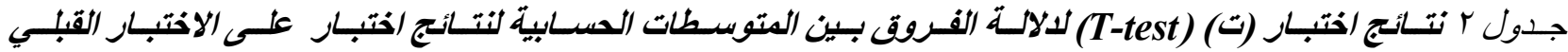
والبعدي

\begin{tabular}{|c|c|c|c|c|c|c|c|}
\hline الدلالة & الحرية درجـــــات & 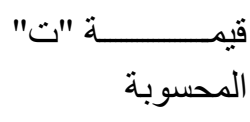 & العـد & 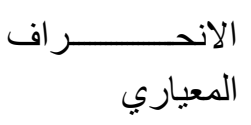 & الحسابي & & الأبعاد \\
\hline & \multirow[b]{2}{*}{29} & \multirow[b]{2}{*}{-6.964} & 30 & 3.448 & 108.90 & قبلي & \multirow[b]{2}{*}{ الكلي } \\
\hline 0 & & & 30 & 3.329 & 114.77 & بعـــ & \\
\hline \multirow{2}{*}{$\begin{array}{r}0.00 \\
0\end{array}$} & \multirow[b]{2}{*}{29} & \multirow[b]{2}{*}{-5.149} & 30 & 1.671 & 32.97 & قبلي & \multirow{2}{*}{ 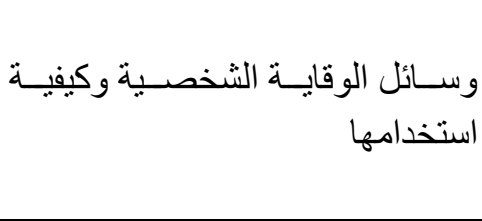 } \\
\hline & & & 30 & 1.783 & 35.17 & بعـد & \\
\hline \multirow{2}{*}{$\begin{array}{r}0.00 \\
4\end{array}$} & \multirow[b]{2}{*}{29} & \multirow[b]{2}{*}{-3.130} & 30 & 2.260 & 26.83 & قبلي & \multirow{2}{*}{ مفهـوم الســلامة المهنيــة ومخــاطر } \\
\hline & & & 30 & 1.717 & 28.47 & بيـــ بـ & \\
\hline
\end{tabular}




\begin{tabular}{|c|c|c|c|c|c|c|c|}
\hline \multirow{2}{*}{$\begin{array}{r}0.00 \\
3\end{array}$} & \multirow[b]{2}{*}{29} & \multirow[b]{2}{*}{-3.293} & 30 & 1.217 & 24.03 & قبلي & \multirow{2}{*}{ الإخلاء } \\
\hline & & & 30 & 1.691 & 25.37 & بعـد & \\
\hline \multirow{2}{*}{$\begin{array}{r}0.08 \\
7\end{array}$} & \multirow[b]{2}{*}{29} & \multirow[b]{2}{*}{-1.769} & 30 & 1.285 & 25.07 & قبلي & \multirow[b]{2}{*}{ مخاطر تسرييات الغاز } \\
\hline & & & & 1.431 & 25.77 & بيسـ & \\
\hline
\end{tabular}

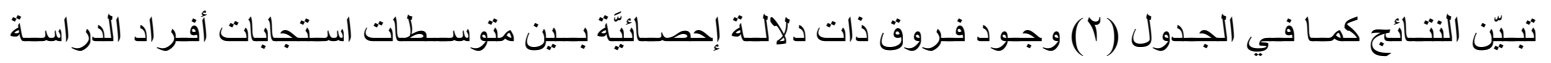

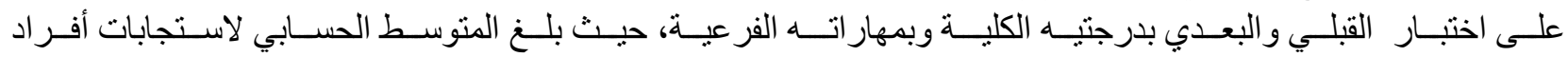

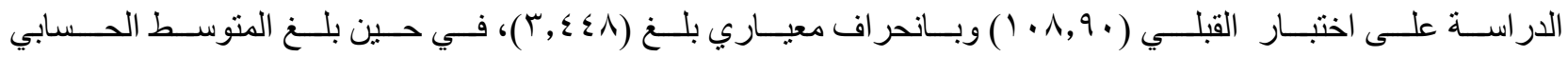

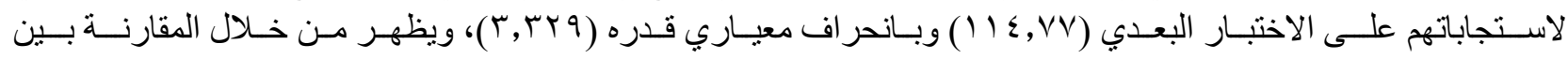
المتوسطين الحسابيين وجود فرق كبير بينها.

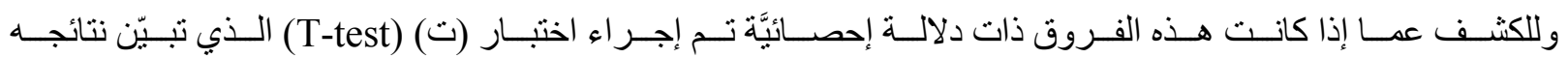

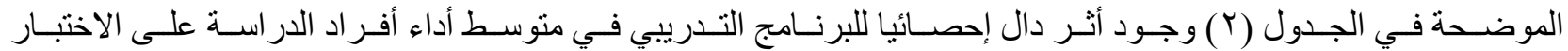

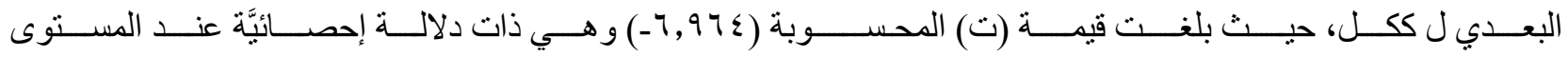

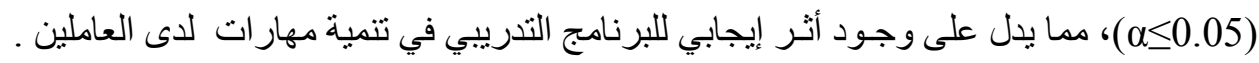

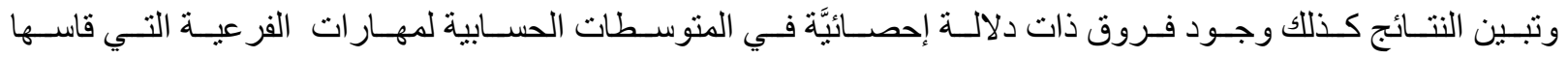

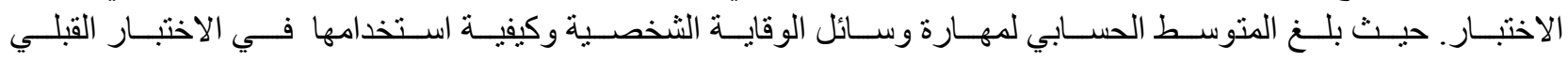

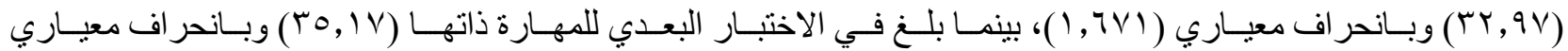

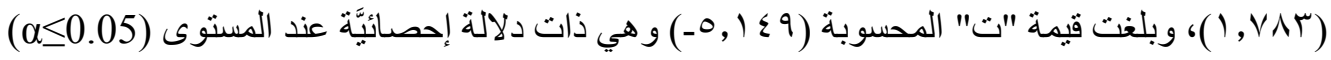

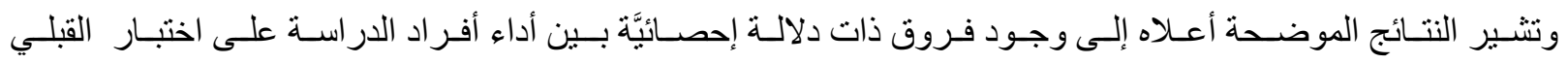

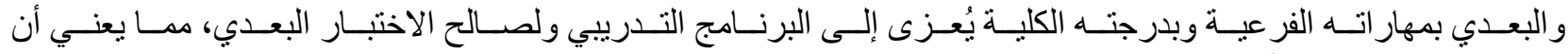

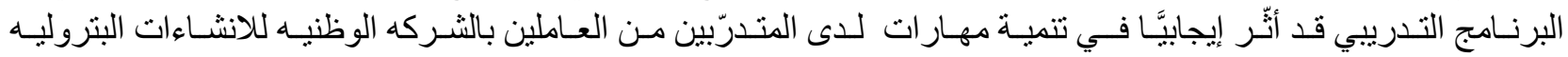
بدوله الامار ات العربيه المتحده برجع لعامل الخبره.

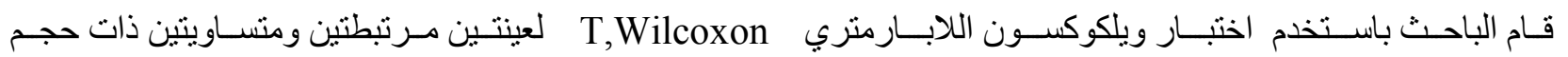

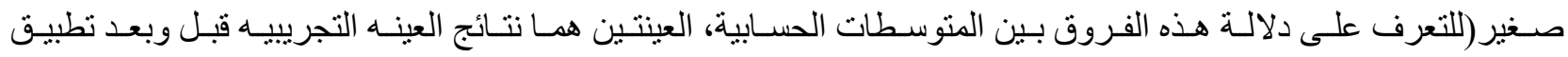

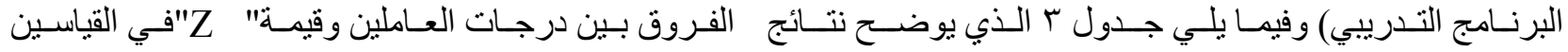
القبلي و البعدي باتخاذ عامل الخبره كعامل محدد.

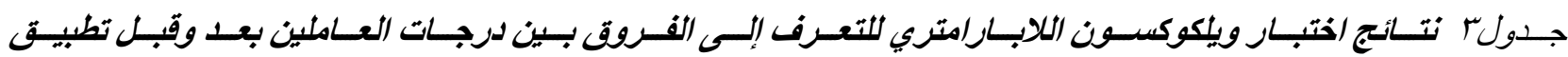

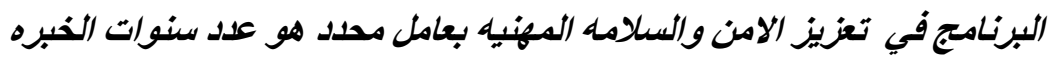




\begin{tabular}{|c|c|c|c|c|c|}
\hline & لــلـالا & " المحسوبة & العـد & الرتب & الأبعاد \\
\hline \multirow{2}{*}{$\begin{array}{r}0.00 \\
\text {, }\end{array}$} & \multirow{2}{*}{$\begin{array}{r}r, 7 \\
0\end{array}$} & 30 & $r$ & السالبه & \multirow{2}{*}{ 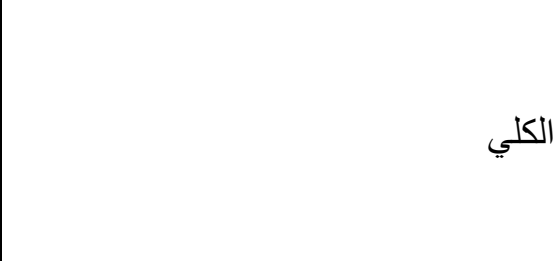 } \\
\hline & & 30 & $r \wedge$ & الموتبه & \\
\hline \multirow{2}{*}{$\begin{array}{r}0.00 \\
0\end{array}$} & \multirow{2}{*}{$\begin{array}{r}r, r \\
0\end{array}$} & 30 & $r$ & السالبه & \multirow{2}{*}{ 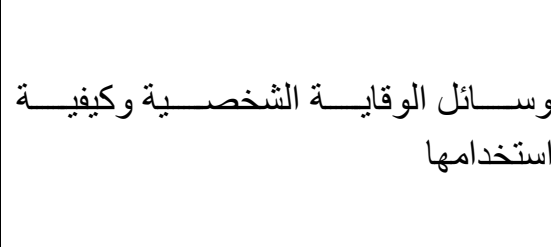 } \\
\hline & & 30 & $r \wedge$ & الرتو الرتبه & \\
\hline \multirow{2}{*}{$\begin{array}{r}0.00 \\
r\end{array}$} & \multirow{2}{*}{$\begin{array}{r}r, \varepsilon \\
0\end{array}$} & 30 & . & 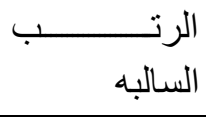 & \multirow{2}{*}{ مفهوم السلامة المهنية ومخاطر العمل } \\
\hline & & 30 & r. & الروتبه & \\
\hline \multirow{2}{*}{$\begin{array}{r}0.00 \\
,\end{array}$} & \multirow{2}{*}{$\begin{aligned} r, r \\
\end{aligned}$} & 30 & $r$ & 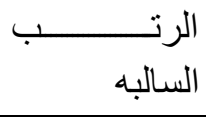 & \multirow{2}{*}{ الإخلاء الإجـــار عات المتخـــــة فــــــــــالات } \\
\hline & & 30 & $r \wedge$ & الموتبه & \\
\hline \multirow{2}{*}{$\varepsilon 0.0$} & r, & 30 & 1 & السالبه & \multirow{2}{*}{ مخاطر تسرييات الغاز } \\
\hline & 7 & 30 & $r q$ & الموجبه & \\
\hline
\end{tabular}

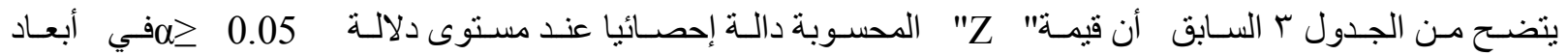

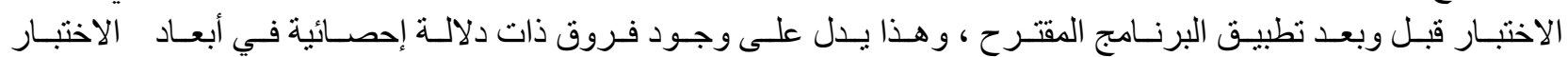

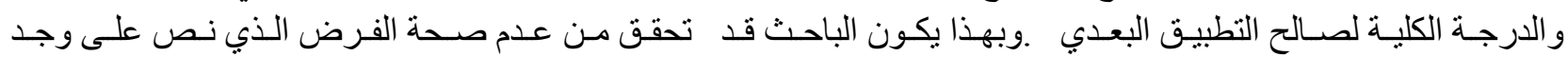

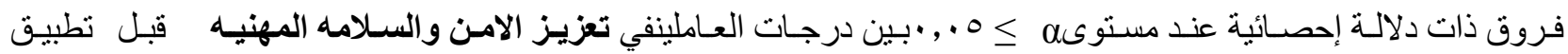

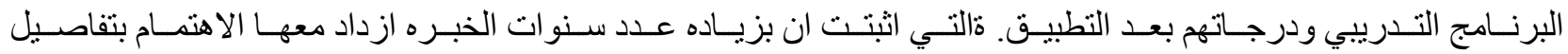
البرنانج وذياده الاستفاده

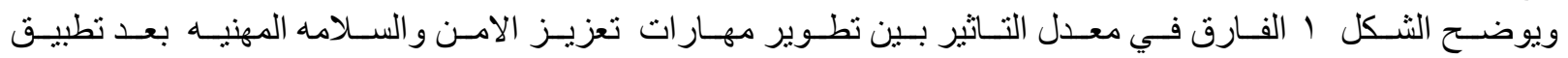

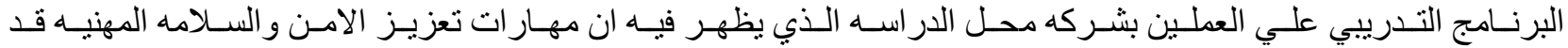

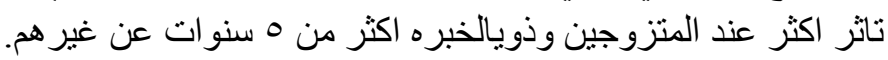




\section{معدل التاثير معبر عنه بايتا تربيع}

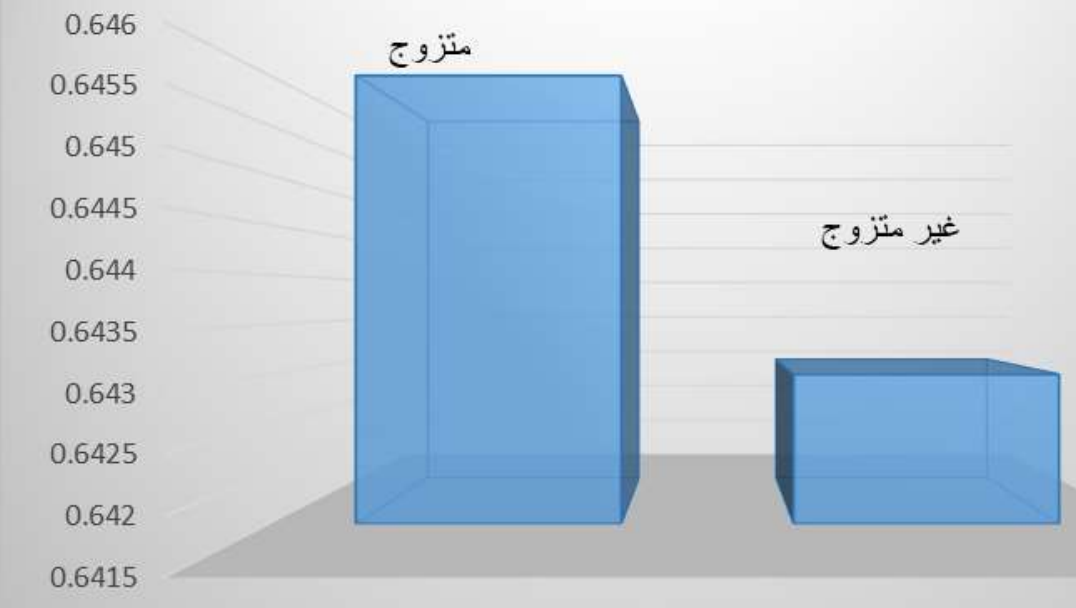

شكل ا ـ معدل التاثير في تطوير مهارات ومهارات تعزيز الامن والسلامه المهنيه للمعلمين بعد البرنامج

الاستنتاجات و التوصيات

ومن النتائج التي توصلت لها الدر اسه يمكن الخروج بعدد من الاستنتاجات و التوصيات الاتيه

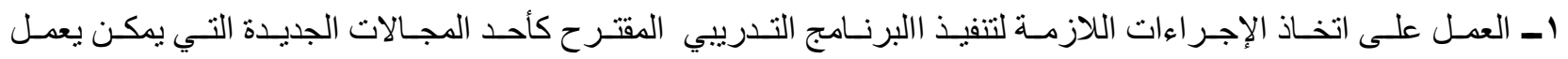

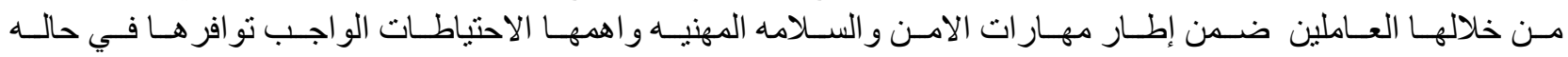

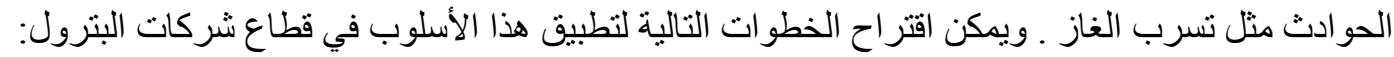

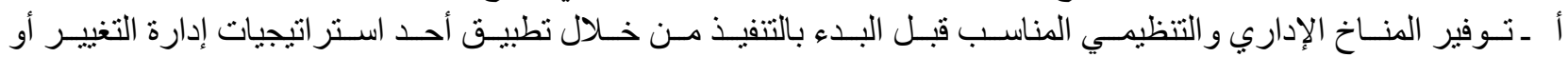

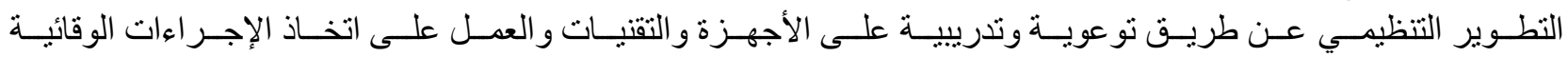
و الاحتياطية التي تقلل من مخاطر العمل.

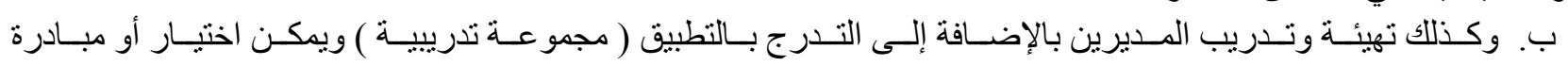

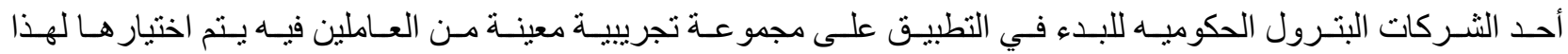

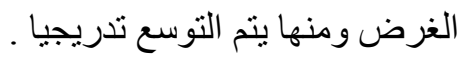

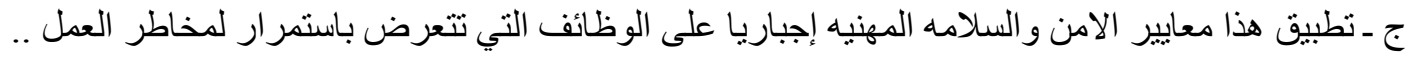

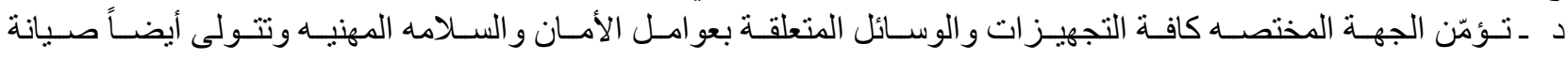
الآلات و المعدات وتتحمل الجهة نفسها مصاريف التدريب المستمر للعاملين بها.

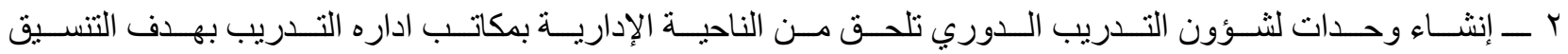

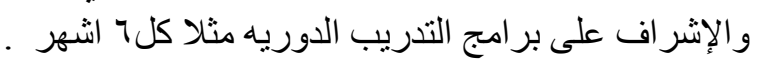

\section{قائمه المراجع}

Abdallah, A. (2018). 1614b Economics of sustainability, occupational health and safety. In: BMJ Publishing Group Ltd.

Amiri, D., Sann, L. M., Adon, M. Y., Mukhtar, F., Idris, K., Kuhn, K., \& Kamari, A. A. J. A. S. S. (2015). Relationship of psychosocial safety climate and workplace psychosocial risks: A randomized trail among personnel of an oil and gas company in Iran. 11(12), 69 . 
Asad, M. M., Hassan, R. B., Sherwani, F., Ibrahim, N. H., \& Soomro, Q. M. (2018). Level of satisfaction for occupational safety and health training activities: $a$ broad spectrum industrial survey. Paper presented at the Journal of Physics: Conference Series.

Demeritt, D., Rothstein, H., Beaussier, A.-L., Howard, M. J. E., \& A, P. (2015). Mobilizing risk: explaining policy transfer in food and occupational safety regulation in the UK. 47(2), 373-391 .

Dhillon, B. S. (2016). Safety and reliability in the oil and gas industry: A practical approach: CRC Press.

Gharpurea, S., Roya, S., Purang, P., \& Bhattacharyya, S. J. R. A. i. P .S. (2018). Role of Cultural Dimensions in Safety Performance of Global Oil and Gas Industry. 5 .(1)

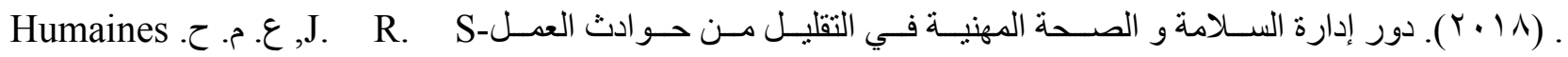

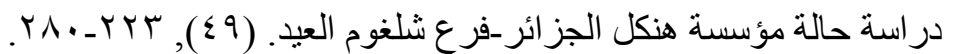

Mason, K. L., Retzer, K. D., Hill, R., Lincoln, J. M. J. M. M., \& report, m. w. (2015). Occupational fatalities during the oil and gas boom-United States, 2003-2013. 64(20), 551 .

Muhammad, A. H., Helal, A. S. J. J. o. P. R., \& Studies. (2018). Effects of Occupational Exposure on Lung Function Tests in Old Process Plant Units workers, North Oil Company, Iraq. (21), E16-E27.

Paterson, J. (2017). Behind the Mask: Regulating health and safety in Britain's offshore oil and gas industry: Routledge.

Rodrigues, M. A., Rubio-Romero, J. C., Arezes, P., \& Soriano-Serrano, M. J. D. (2016). Occupational risk assessment at Olive Oil Mills: Limitations and new perspectives. 83(196), 21-26.

Zeb, A., Riaz, H., Tahir, Q., Anwar, I., Altaf, A. J. I. J. o. H. E., \& Policy. (2017). Assessment of Knowledge, Attitude and Practices Regarding Occupational Safety Among Onshore Oil Rig Workers in District Karak, KPK, Pakistan. 2(3), 134 .

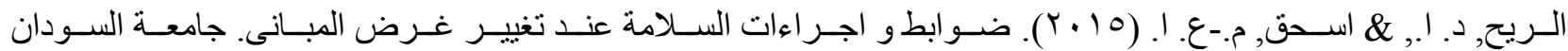
للعلوم و التكنولوجيا,

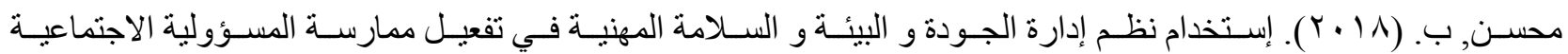

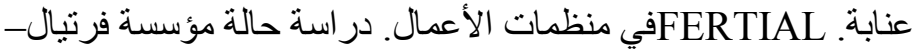

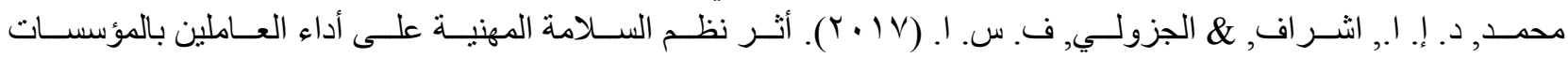
الصناعية (در اسة على صو امع البنأك الزر اعي بورتنسو العان).

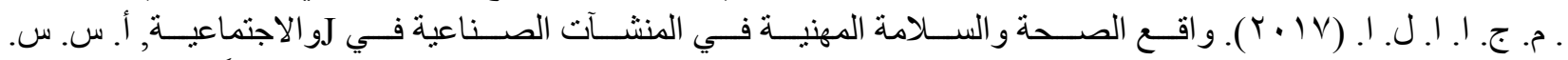
فلسطين-محافظة طولكرم نموذجاً. (7 (1) ).

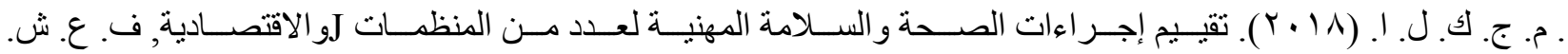

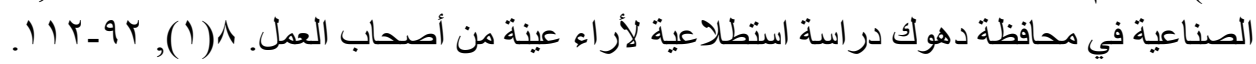

